\title{
Eigenmodes in Two Simplified Chamber Structures Studied for Spurious Microwaves in the APS Storage Ring Beam Chamber
}

\author{
Xiang Sun and Glenn Decker
}

April 30, 2003

\section{Abstract}

The vertical readback errors are one order of magnitude greater than the horizontal ones in the APS storage ring beam chamber. To learn and solve this problem, we simulate the eigenmodes in two chamber structures, which are simplified from the APS storage ring beam chamber, and find their dependence on the variation of the chamber structures. These two structures are introduced as the solutions to separate and then restrain the spurious microwave modes by using a metal short block and a plate inside the chamber. The short block can shift and separate the frequencies of every mode evidently.

\section{Introduction}

There are systematic errors in the beam position monitors in the APS storage ring beam chamber. The vertical readback errors are one order of magnitude greater than the horizontal ones. This phenomenon can be attributed to "rogue" microwave modes that appear around $350 \mathrm{MHz}$ and orientate vertically $[1,2]$. We need to learn the phenomena and then solve this problem.

Figure 1 shows the cross section of the APS storage ring vacuum chamber. We simplified this chamber in Figures 2 and 3.

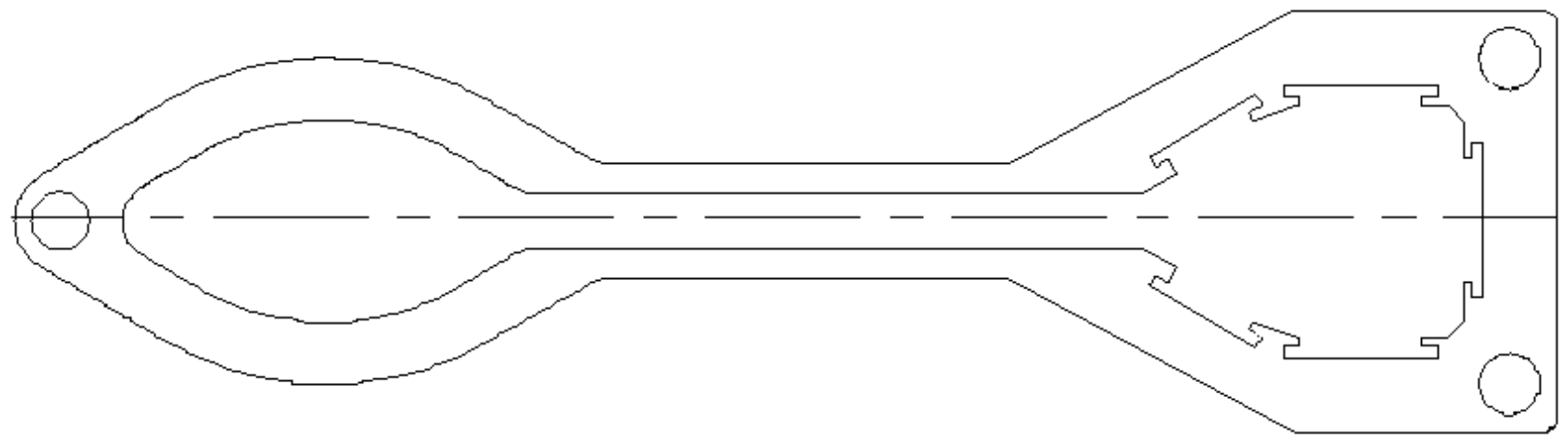

Figure 1. Storage ring vacuum chamber cross section [1].

Figure 2 shows the scheme of a simplified chamber structure with a short block of length $L$ at the rear right corner. Figure 3 shows the scheme of a simplified chamber structure with a short plate of length L away from the end at the rear right corner. Both the length $L$ of the metal block in Figure 2 and the position $L$ of the metal plate in Figure 3 are variable.

We are going to solve the frequencies and the frequency shift for the first a few eigenmodes in two simplified chamber structures and find their dependence on L. We also calculate the transverse electric field $\mathrm{E}_{\mathrm{y}}$ at two points BPM+ and BPM shown in Figures 2 and 3 and their dependence on L. The field patterns for the first three modes at different cross sections in Figure 2 are presented. 


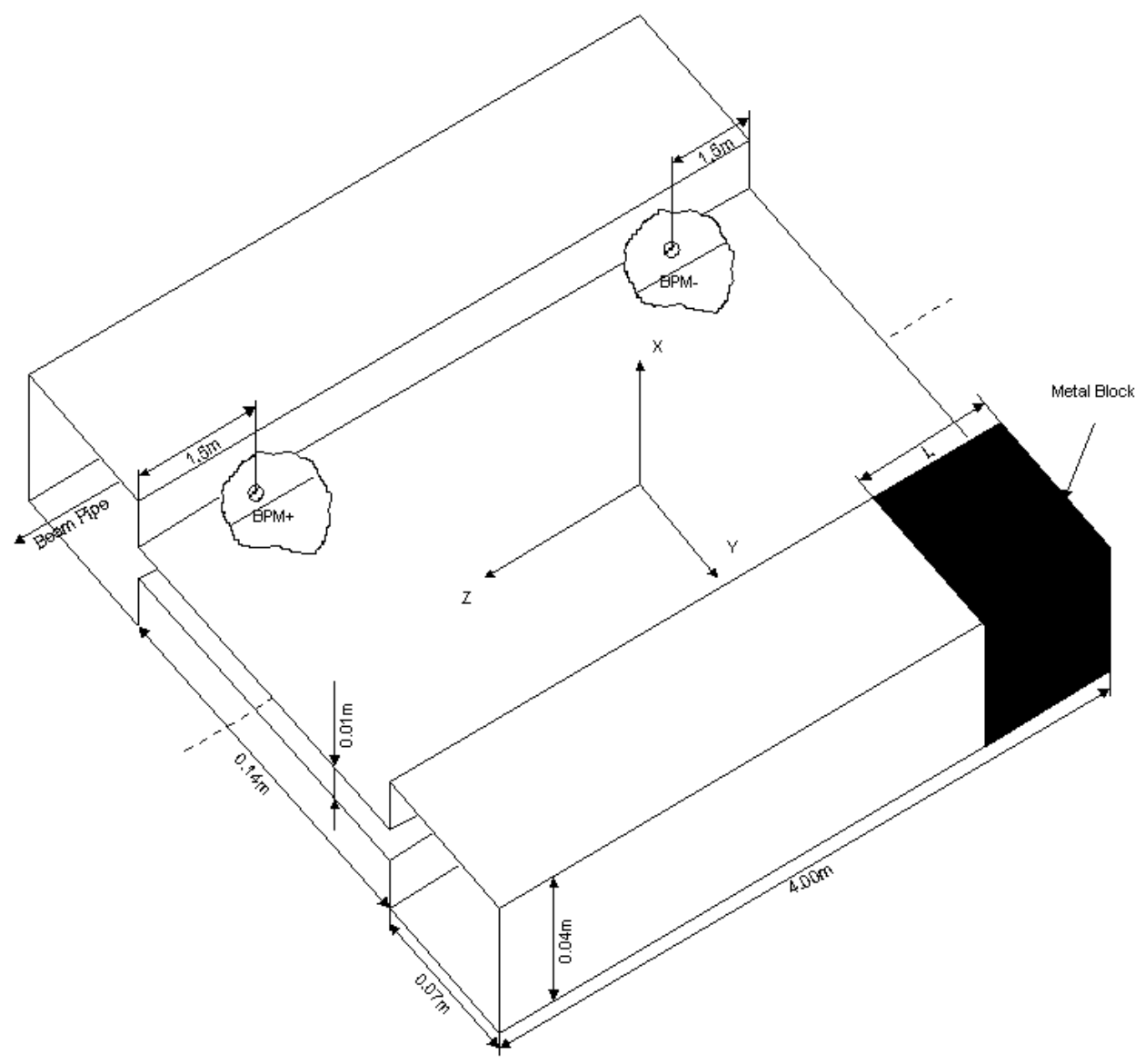

Figure 2. Scheme of a simplified chamber structure with a short block of length $\mathrm{L}$ at the rear right corner. 


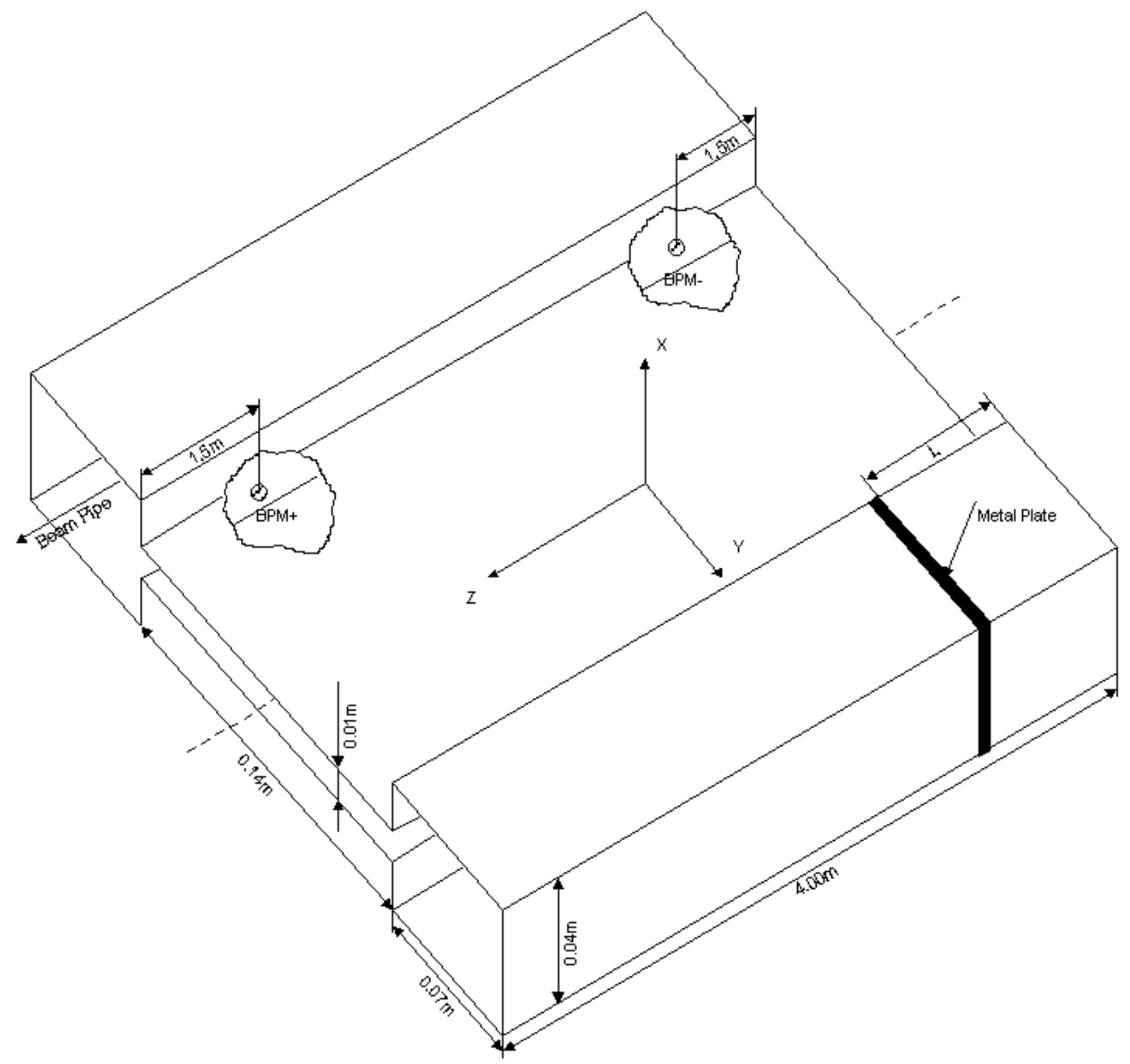

Figure 3. Scheme of a simplified chamber structure with a short plate of length L away from the end at the rear right corner.

\section{MAFIA Eigenmode Simulation for the Simplified Chamber with a Short Block}

A 3-D software MAFIA [3] is used to do this simulation, and the results are convergent at 160,000 grids.

We simulate the frequencies of the first five eigenmodes and their shift in the simplified chamber structure with a short block of length $L$ at the rear right corner (shown in Figure 2) and find their dependence on L. The results are shown in Table 1 and Figure 4.

Table 1. Frequencies of the first five eigenmodes and their dependence on $\mathrm{L}$ in a simplified chamber structure with a short block of length $\mathrm{L}$ at the rear right corner

$($ meshes $=160,000)$

\begin{tabular}{|c|c|c|c|c|c|}
\hline No. & mode & $\mathrm{F} / \mathrm{MHz}(\mathrm{L}=0.0 \mathrm{~m})$ & $\mathrm{F} / \mathrm{MHz}(\mathrm{L}=0.5 \mathrm{~m})$ & $\mathrm{F} / \mathrm{MHz}(\mathrm{L}=1.0 \mathrm{~m})$ & $\mathrm{F} / \mathrm{MHz}(\mathrm{L}=1.5 \mathrm{~m})$ \\
\hline 1 & $\mathrm{TE}_{101}$ & 308.99 & 309.59 & 310.60 & 312.26 \\
\hline 2 & $\mathrm{TE}_{102}$ & 315.73 & 318.07 & 322.00 & 328.33 \\
\hline 3 & $\mathrm{TE}_{103}$ & 326.66 & 331.72 & 340.12 & 353.46 \\
\hline 4 & $\mathrm{TE}_{104}$ & 341.38 & 349.93 & 363.96 & 385.84 \\
\hline 5 & $\mathrm{TE}_{105}$ & 359.41 & 371.99 & 392.43 & 423.72 \\
\hline
\end{tabular}




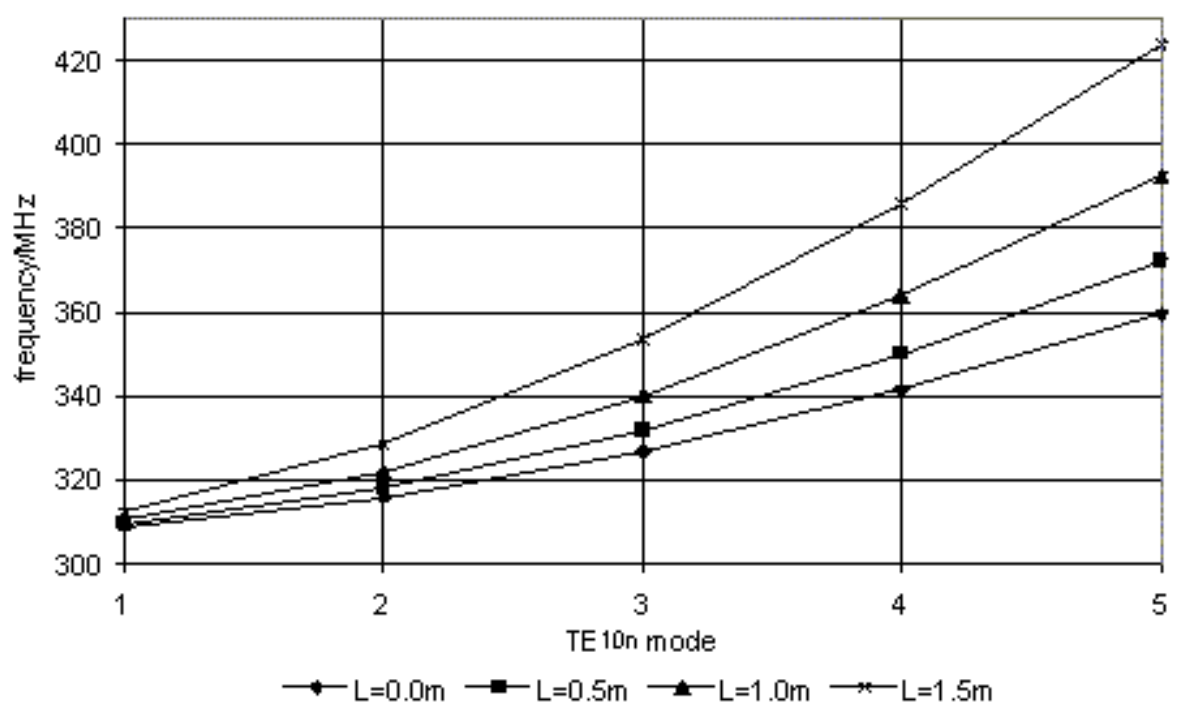

Figure 4. Frequencies of the first five eigenmodes and their dependence on L in a simplified chamber structure with a short block of length $L$ at the rear right corner.

The spurious microwave modes around $350 \mathrm{MHz}$ are $\mathrm{TE}_{10}$-like. Evidently, the short block can shift and separate the frequencies of every mode, especially for the higher modes. The longer the length $\mathrm{L}$ is, the more the frequency shifts. It will be helpful to restraint the spurious microwave modes and improve the readbacks.

\section{Transverse Electric Field $E_{y}$ at Two Points in the Simplified Chamber with a Short Block}

We calculate the transverse electric field $\mathrm{E}_{\mathrm{y}}$ at two points $\mathrm{BPM}_{+}$and $\mathrm{BPM}$ - in the simplified chamber structure with a short block shown in Figure 2 and find their dependence on L. The energy is normalized to $\varepsilon_{0} / 4$ Joule. The results are shown in Table 2 and Figure 5.

Table 2. $\mathrm{E}_{\mathrm{y}}$ at $\mathrm{x}=-0.07 \mathrm{~m}, \mathrm{y}=0 \mathrm{~m}, \mathrm{z}= \pm 1.5 \mathrm{~m}$ normalized to the energy of $\varepsilon_{0} / 4$ Joule. The simplified chamber is shorted by a metal block of length $\mathrm{L}$ at the rear right corner.

\begin{tabular}{|c|r|r|r|r|r|r|r|r|}
\hline $\begin{array}{c}\mathrm{E}_{\mathrm{y}} \\
(\mathrm{V} / \mathrm{m})\end{array}$ & \multicolumn{2}{|c|}{$\mathrm{L}=0.0 \mathrm{~m}$} & \multicolumn{2}{c|}{$\mathrm{L}=0.5 \mathrm{~m}$} & \multicolumn{2}{c|}{$\mathrm{L}=1.0 \mathrm{~m}$} & \multicolumn{2}{c|}{$\mathrm{L}=1.5 \mathrm{~m}$} \\
\hline Mode & $\mathrm{z}=1.5 \mathrm{~m}$ & $\mathrm{z}=-1.5 \mathrm{~m}$ & $\mathrm{z}=1.5 \mathrm{~m}$ & $\mathrm{z}=-1.5 \mathrm{~m}$ & $\mathrm{z}=1.5 \mathrm{~m}$ & $\mathrm{z}=-1.5 \mathrm{~m}$ & $\mathrm{z}=1.5 \mathrm{~m}$ & $\mathrm{z}=-1.5 \mathrm{~m}$ \\
\hline $\mathrm{TE}_{101}$ & 6.31 & 6.31 & 7.47 & 1.22 & 9.26 & 0.01 & 11.87 & 0.00 \\
\hline $\mathrm{TE}_{102}$ & 11.65 & 11.65 & 13.50 & 2.44 & 16.12 & 0.02 & 19.40 & 0.00 \\
\hline $\mathrm{TE}_{103}$ & 15.22 & 15.22 & 16.94 & 3.69 & 18.82 & 0.04 & 19.83 & 0.00 \\
\hline $\mathrm{TE}_{104}$ & 16.48 & 16.48 & 17.13 & 4.98 & 16.67 & 0.06 & 13.06 & 0.00 \\
\hline $\mathrm{TE}_{105}$ & 15.22 & 15.22 & 14.04 & 6.32 & 10.24 & 0.09 & 1.60 & 0.00 \\
\hline
\end{tabular}


EY of TE101 for different $L$

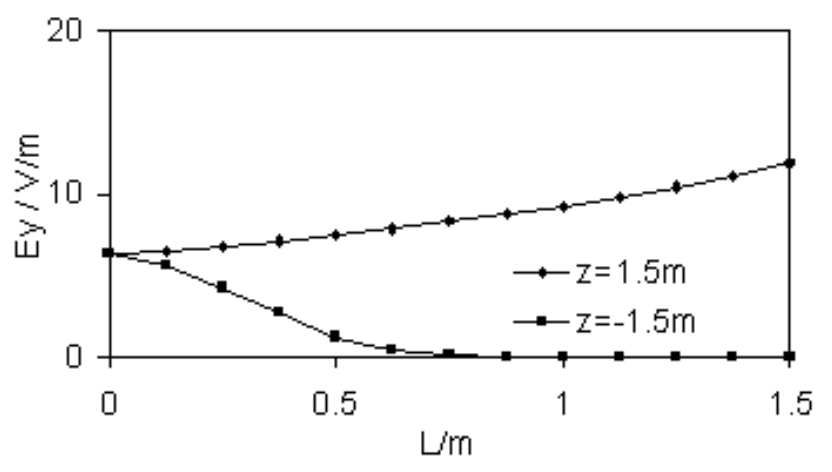

Ey of TE103 for different $L$

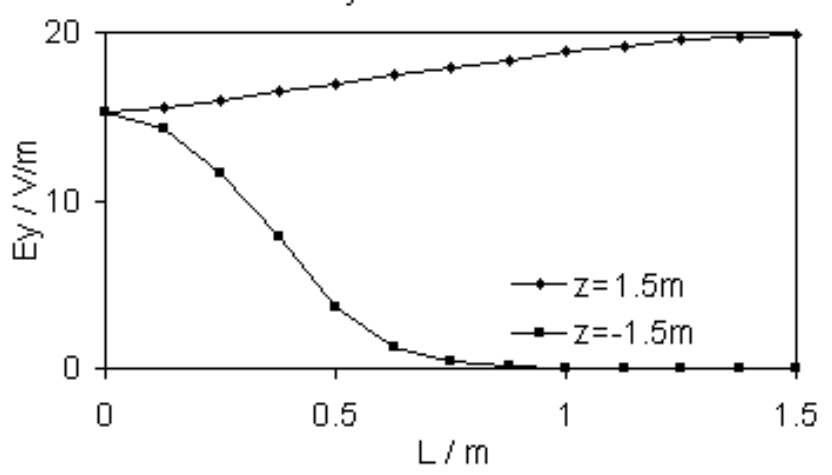

Ey of TE10s for different $L$

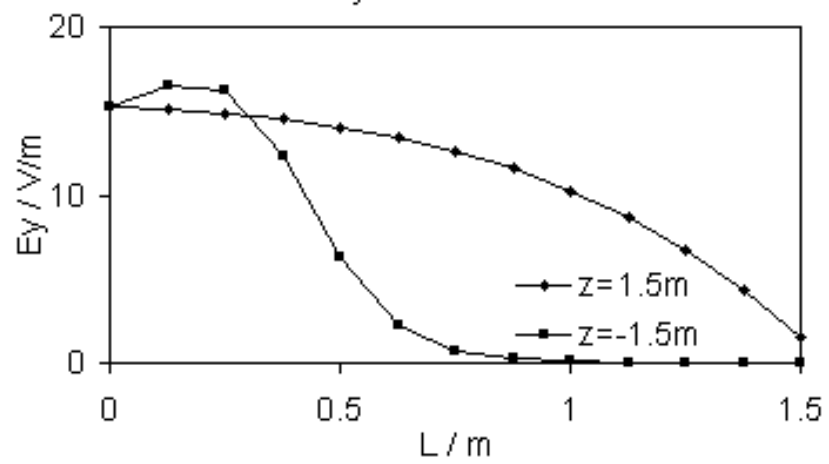

Ey of TE102 for different $L$

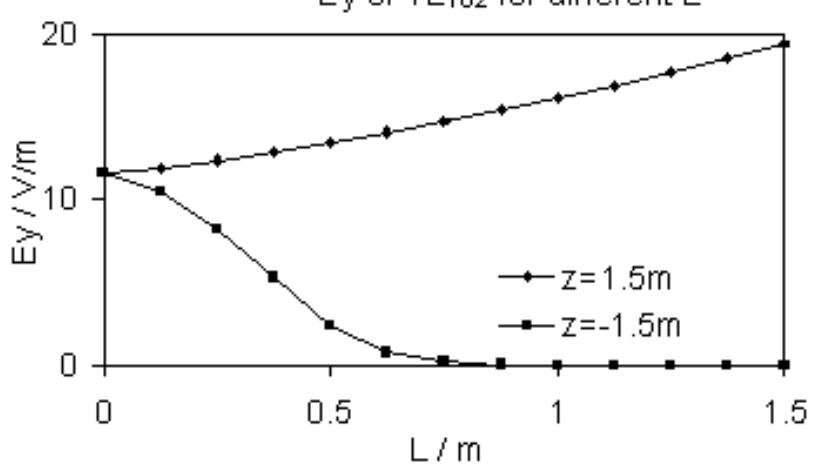

Ey of TE104 for different $L$

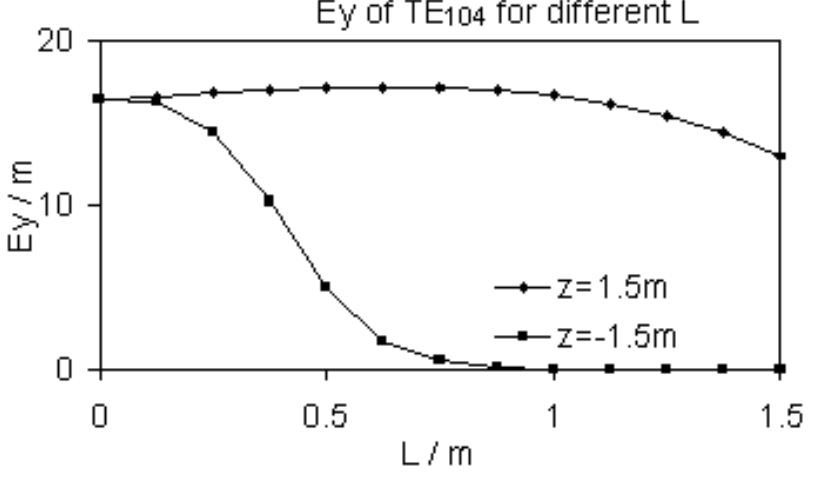

Figure 5. $\mathrm{E}_{\mathrm{y}}$ of the first five eigenmodes at two points in a simplified chamber structure with a short block of length $\mathrm{L}$ at the rear right corner.

\section{MAFIA Eigenmode Simulation for the Simplified Chamber with a Short Plate}

We simulate the frequencies of the first five eigenmodes and their shift in a simplified chamber structure with a short plate shown in Figure 3 and find their dependence on L. The results are shown in Table 3 and Figure 6. 
Table 3. Frequencies of the first five eigenmodes and their dependence on $\mathrm{L}$ in a simplified chamber structure with a short plate of length $\mathrm{L}$ away from the end of the chamber at the rear right corner (meshes $=160,000)$

\begin{tabular}{|c|c|c|c|c|c|}
\hline No. & Mode & $\mathrm{F} / \mathrm{MHz}(\mathrm{L}=0.0 \mathrm{~m})$ & $\mathrm{F} / \mathrm{MHz}(\mathrm{L}=0.5 \mathrm{~m})$ & $\mathrm{F} / \mathrm{MHz}(\mathrm{L}=1.0 \mathrm{~m})$ & $\mathrm{F} / \mathrm{MHz}(\mathrm{L}=1.5 \mathrm{~m})$ \\
\hline 1 & $\mathrm{TE}_{101}$ & 308.99 & 309.53 & 310.49 & 312.03 \\
\hline 2 & $\mathrm{TE}_{102}$ & 315.73 & 317.85 & 321.41 & 320.46 \\
\hline 3 & $\mathrm{TE}_{103}$ & 326.66 & 331.17 & 334.23 & 328.08 \\
\hline 4 & $\mathrm{TE}_{104}$ & 341.38 & 348.74 & 341.38 & 350.73 \\
\hline 5 & $\mathrm{TE}_{105}$ & 359.42 & 369.33 & 363.27 & 361.49 \\
\hline
\end{tabular}

Frequency for differert $L$

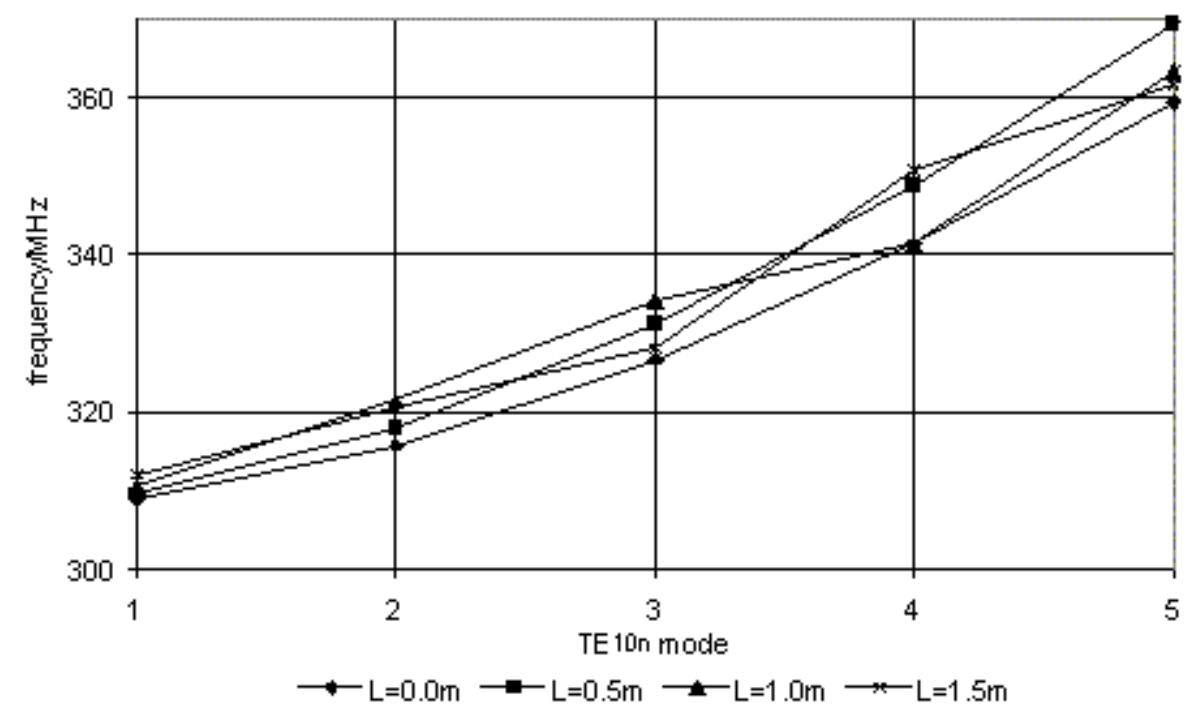

Figure 6. Frequencies of the first five eigenmodes and their dependence on $\mathrm{L}$ in a simplified chamber structure with a short plate of length L away from the end of the chamber at the rear right corner.

The spurious microwave modes around $350 \mathrm{MHz}$ in the APS storage ring beam chamber are $\mathrm{TE}_{10 \mathrm{n}^{-}}$ like. But the short plate almost cannot separate the frequencies of every mode. It can not help to restraint the spurious microwave modes.

\section{Transverse Electric Field $E_{y}$ at Two Points in the Simplified Chamber with a Short Plate}

We calculate the transverse electric field $\mathrm{E}_{\mathrm{y}}$ at two points $\mathrm{BPM}_{+}$and $\mathrm{BPM}$ - and their dependence on L. Normalized condition is for an energy of $\varepsilon_{0} / 4$ Joule. The results are shown in Table 4 and Figure 7. 
Table 4. $\mathrm{E}_{\mathrm{y}}$ at $\mathrm{x}=-0.07 \mathrm{~m}, \mathrm{y}=0 \mathrm{~m}, \mathrm{z}= \pm 1.5 \mathrm{~m}$ normalized to an energy of $\varepsilon_{0} / 4$ Joule. The simplified chamber is shorted by a metal plate of length $\mathrm{L}$ away from the end of the chamber at the rear right corner.

\begin{tabular}{|c|r|r|r|r|r|r|r|r|}
\hline $\begin{array}{c}\mathrm{E}_{\mathrm{y}} \\
(\mathrm{V} / \mathrm{m})\end{array}$ & \multicolumn{2}{|c|}{$\mathrm{L}=0.0 \mathrm{~m}$} & \multicolumn{2}{c|}{$\mathrm{L}=0.5 \mathrm{~m}$} & \multicolumn{2}{c|}{$\mathrm{L}=1.0 \mathrm{~m}$} & \multicolumn{2}{c|}{$\mathrm{L}=1.5 \mathrm{~m}$} \\
\hline Mode & $\mathrm{z}=1.5 \mathrm{~m}$ & $\mathrm{z}=-1.5 \mathrm{~m}$ & $\mathrm{z}=1.5 \mathrm{~m}$ & $\mathrm{z}=-1.5 \mathrm{~m}$ & $\mathrm{z}=1.5 \mathrm{~m}$ & $\mathrm{z}=-1.5 \mathrm{~m}$ & $\mathrm{z}=1.5 \mathrm{~m}$ & $\mathrm{z}=-1.5 \mathrm{~m}$ \\
\hline $\mathrm{TE}_{101}$ & 6.31 & 6.31 & 7.37 & 1.81 & 9.06 & 1.11 & 11.46 & 1.60 \\
\hline $\mathrm{TE}_{102}$ & 11.65 & 11.65 & 13.32 & 3.73 & 15.56 & 4.18 & 4.56 & 20.68 \\
\hline $\mathrm{TE}_{103}$ & 15.22 & 15.22 & 16.72 & 5.90 & 10.09 & 25.55 & 18.68 & 6.78 \\
\hline $\mathrm{TE}_{104}$ & 16.48 & 16.48 & 16.92 & 8.63 & 16.51 & 16.37 & 17.91 & 10.97 \\
\hline $\mathrm{TE}_{105}$ & 15.22 & 15.22 & 13.89 & 12.72 & 16.38 & 6.57 & 9.62 & 20.74 \\
\hline
\end{tabular}
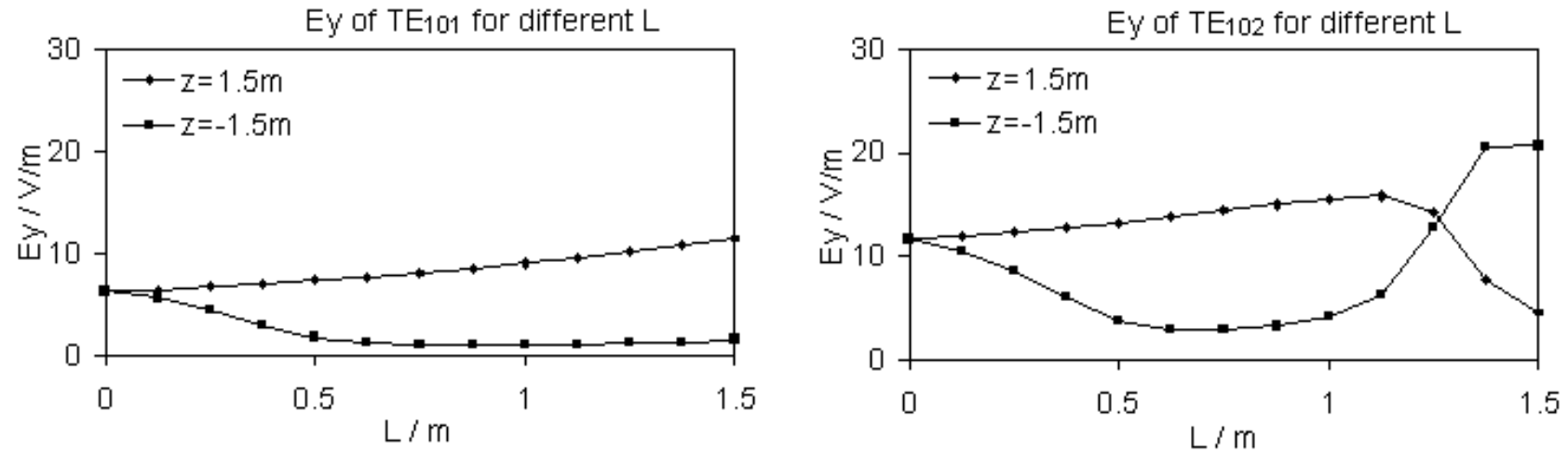

EY of TE 103 for different $L$
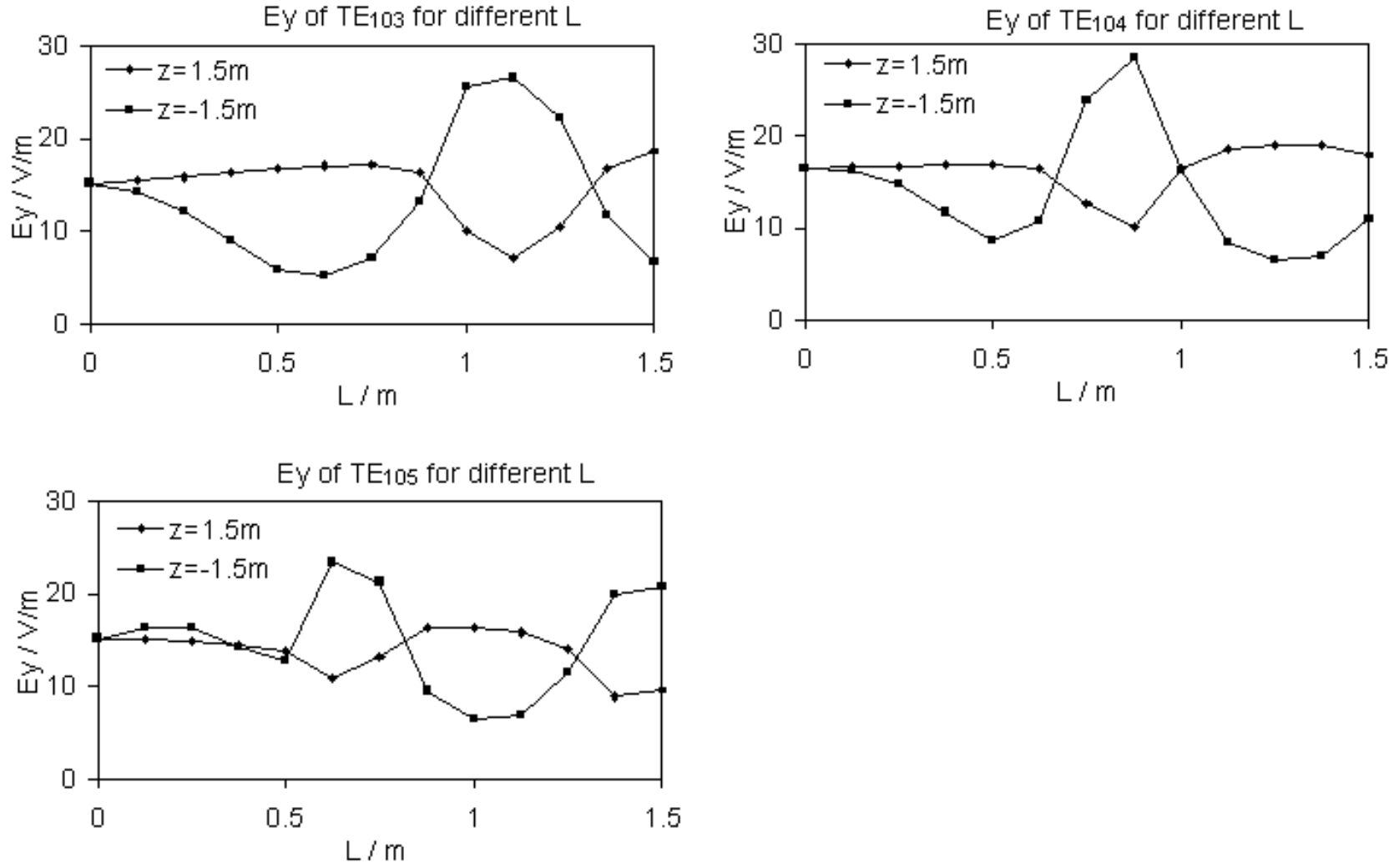

Figure 7. $\mathrm{E}_{\mathrm{y}}$ of the first five eigenmodes at two points in a simplified chamber structure with a short plate of length L away from the end of the chamber at the rear right corner. 
We also calculate the field pattern for the first three modes with $\mathrm{L}=1 \mathrm{~m}$ in the simplified chamber structure with a short block.

Figure 8 shows the 3-D electric and magnetic field pattern of $\mathrm{TE}_{101}$.
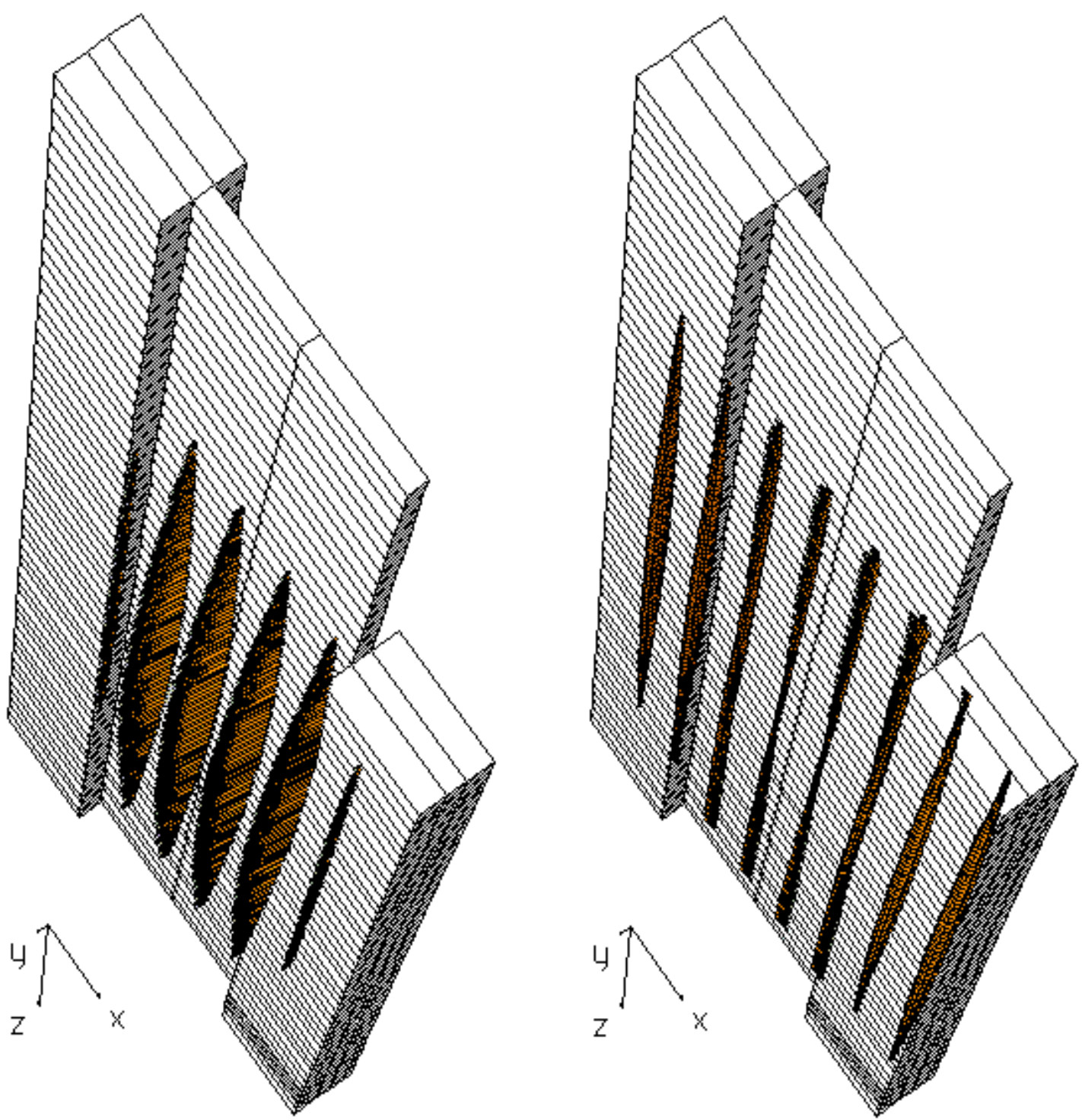

Figure 8. 3-D field pattern of $\mathrm{TE}_{101}$ with $\mathrm{L}=1 \mathrm{~m}$ in the simplified chamber structure with a short block of length $\mathrm{L}$ at the rear right corner. Left is electric fields and right is magnetic fields. 
Figure 9 shows the field pattern of $\mathrm{TE}_{101}$ at different $\mathrm{z}$ cross sections.
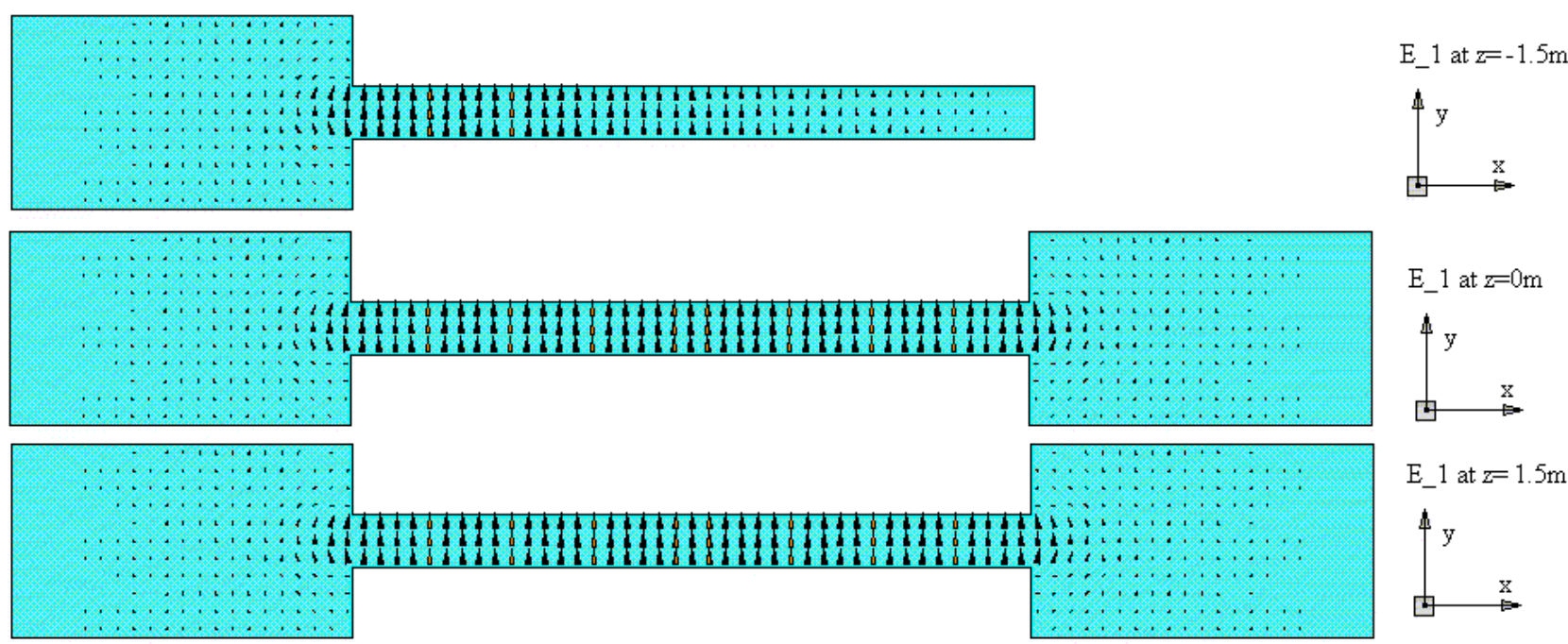

E_1 at $z=1.5 \mathrm{~m}$
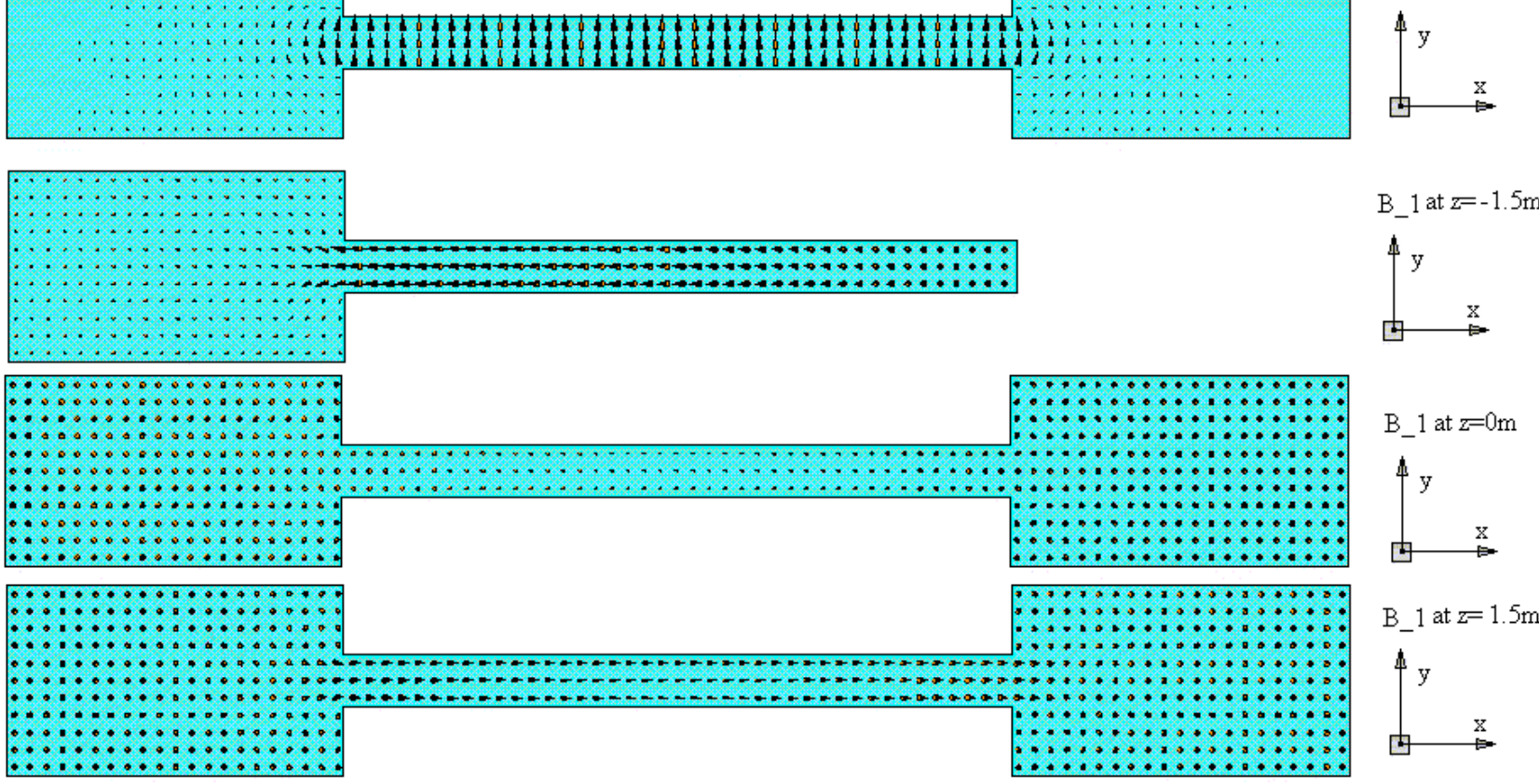

Figure 9. Field pattern of $\mathrm{TE}_{101}$ at different $\mathrm{z}$ cross sections with $\mathrm{L}=1 \mathrm{~m}$ in the simplified chamber structure with a short block of length $\mathrm{L}$ at the rear right corner. Top is electric fields and bottom is magnetic fields. 
Figure 10 shows the $3-\mathrm{D}$ field pattern of $\mathrm{TE}_{102}$.
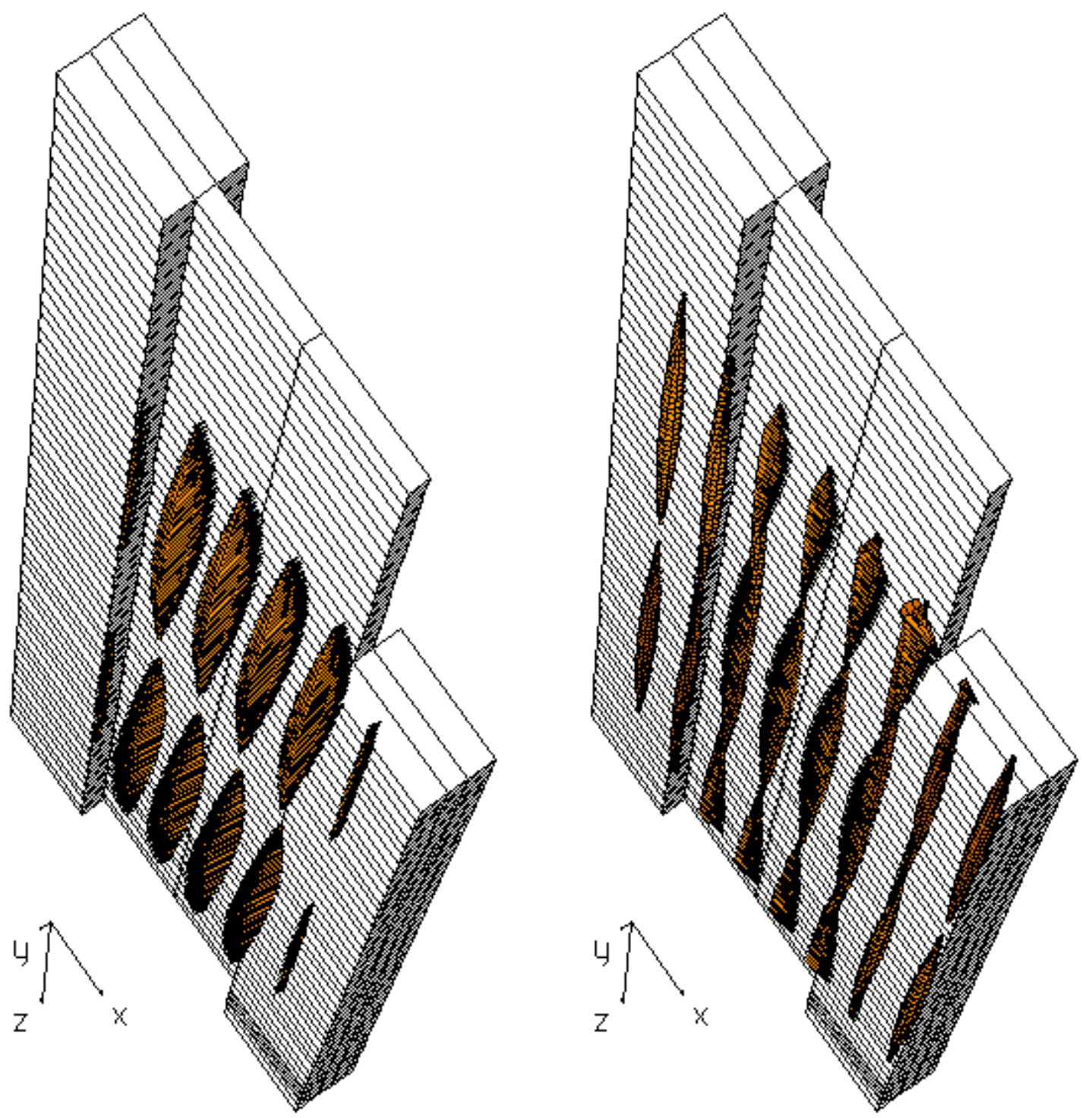

Figure 10. 3-D field pattern of $\mathrm{TE}_{102}$ with $\mathrm{L}=1 \mathrm{~m}$ in the simplified chamber structure with a short block of length $\mathrm{L}$ at the rear right corner. Left is electric fields and right is magnetic fields. 
Figure 11 shows the electric and magnetic field pattern of $\mathrm{TE}_{102}$ at different $\mathrm{z}$ cross sections.

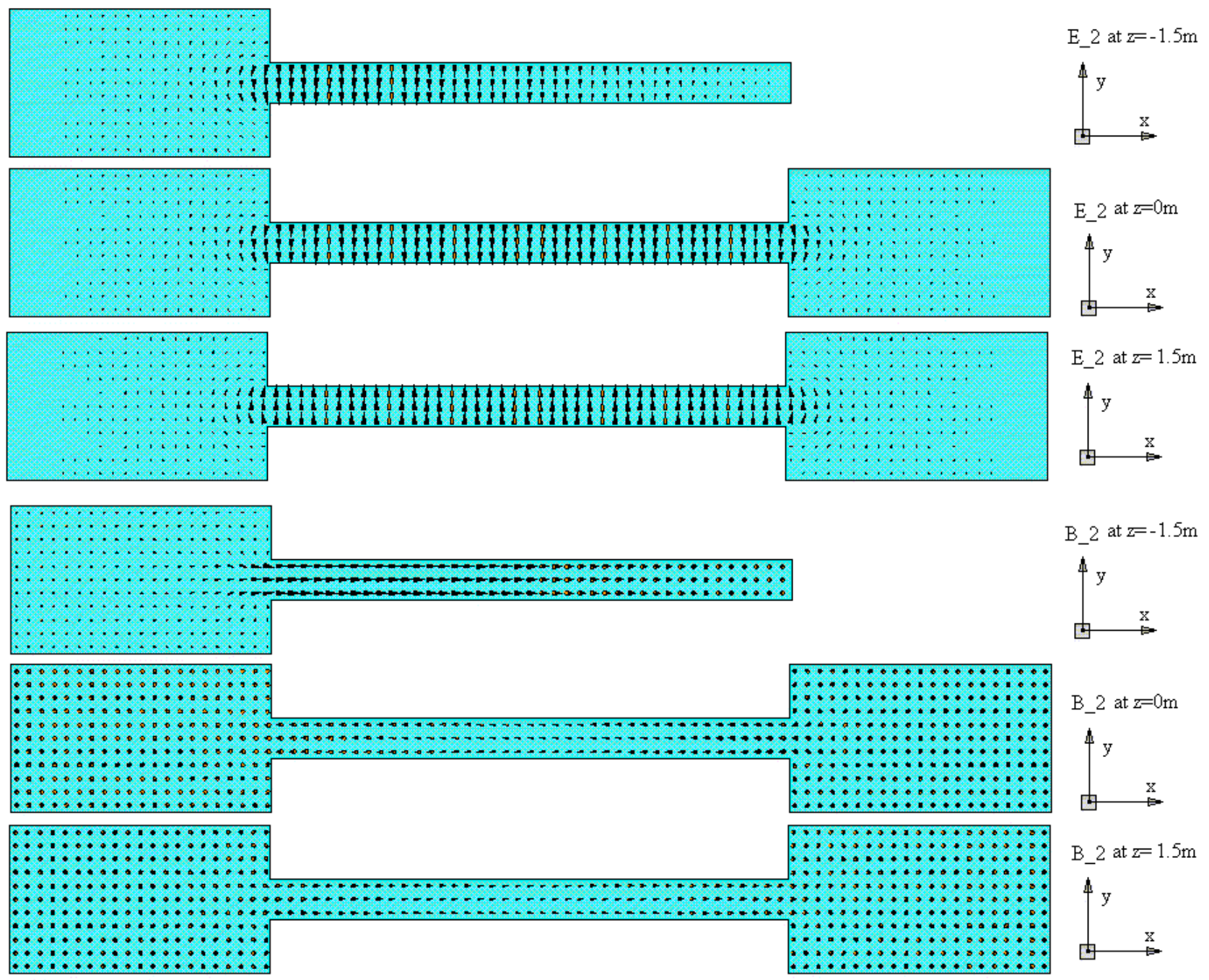

Figure 11. Field pattern of $\mathrm{TE}_{102}$ at different $\mathrm{z}$ cross sections with $\mathrm{L}=1 \mathrm{~m}$ in the simplified chamber structure with a short block of length $\mathrm{L}$ at the rear right corner. Top is electric fields and bottom is magnetic fields. 
Figure 12 shows the 3-D Electric and magnetic field pattern of $\mathrm{TE}_{103}$.
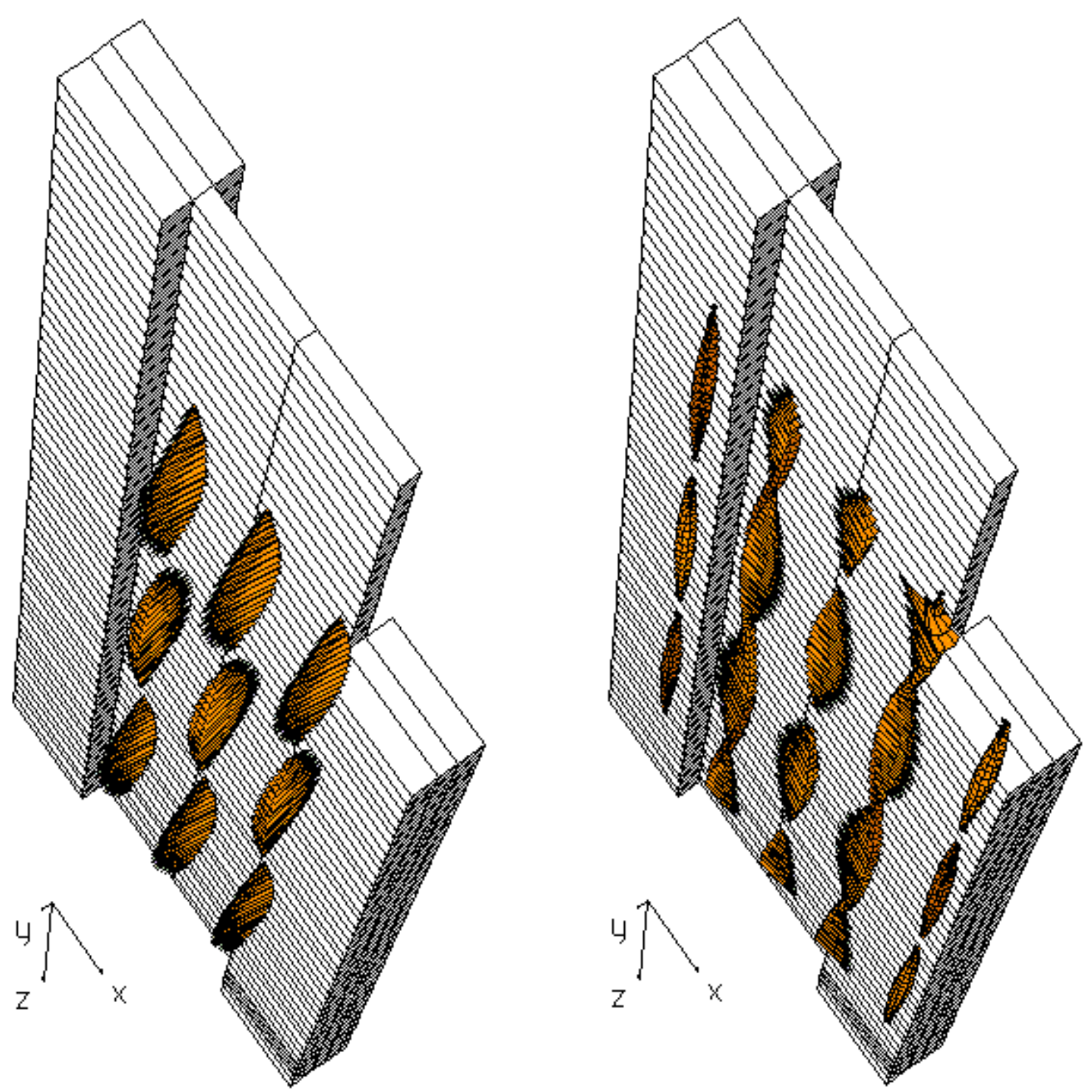

Figure 12. 3-D field pattern of $\mathrm{TE}_{103}$ with $\mathrm{L}=1 \mathrm{~m}$ in the simplified chamber structure with a short block of length $\mathrm{L}$ at the rear right corner. Left is electric fields and right is magnetic fields. 
Figure 13 shows the field pattern of $\mathrm{TE}_{103}$ at different $\mathrm{z}$ cross sections.

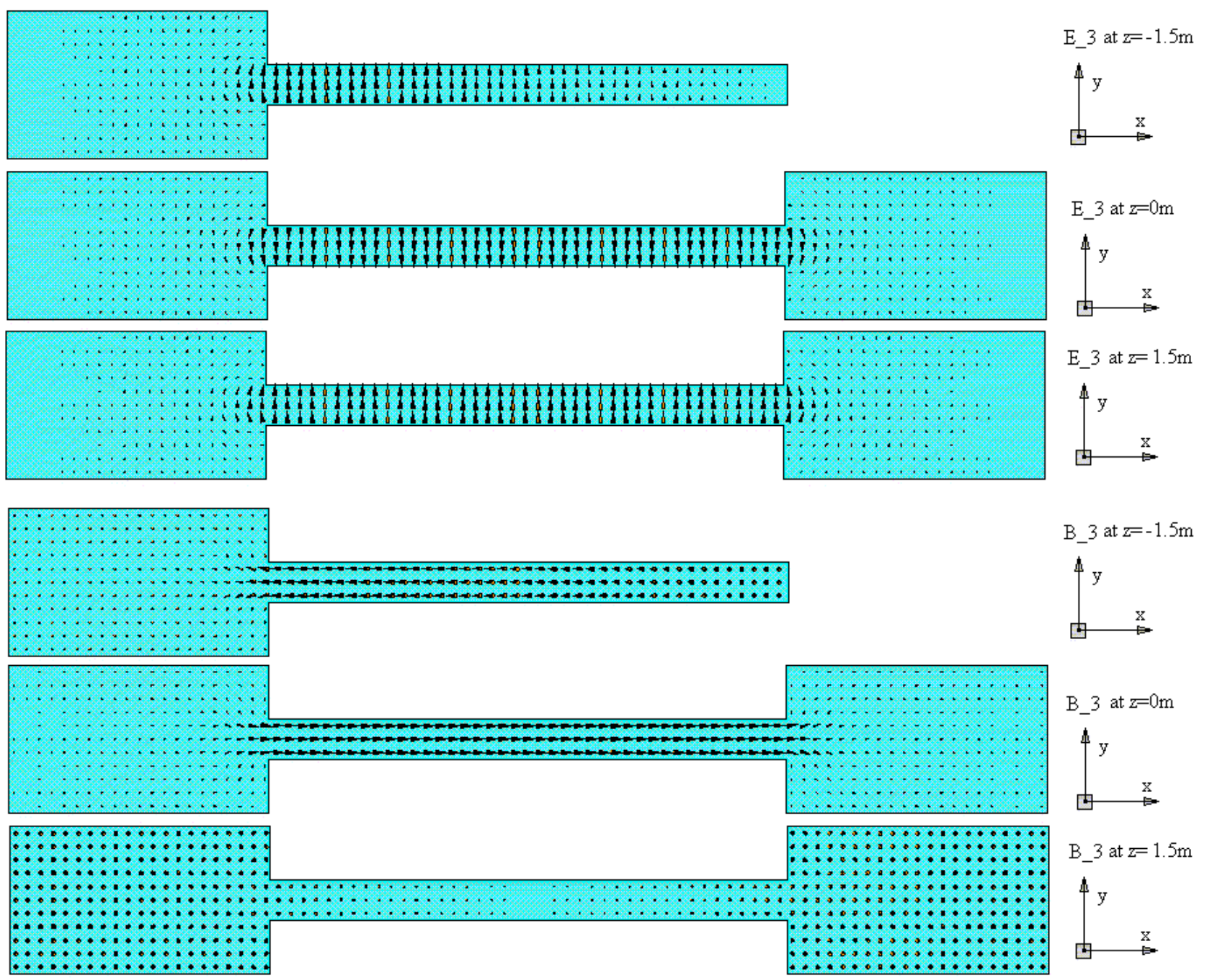

Figure 13. Field pattern of $\mathrm{TE}_{103}$ at different $\mathrm{z}$ cross sections with $\mathrm{L}=1 \mathrm{~m}$ in the simplified chamber structure with a short block of length $L$ at the rear right corner. Top is electric fields and bottom is magnetic fields.

The first three modes are $\mathrm{TE}_{10}$-like, and the electric fields in the ridge waveguide between two chambers are vertical. They cause the vertical readback errors to be one order of magnitude greater than the horizontal ones in the APS storage ring beam chamber

\section{Conclusion}

The spurious microwave modes around $350 \mathrm{MHz}$ in the APS storage ring beam chamber are $\mathrm{TE}_{10 \mathrm{n}^{-}}$ like. Their electric fields are vertical in the ridge waveguide and thus impact on vertical BPM readbacks. The solutions to separate these modes by using a metal short block and a plate have been introduced. The short block can evidently shift and separate the frequencies of every mode, especially for the higher modes. The longer the length $\mathrm{L}$ is, the more the frequency shifts. It will be helpful to restraint the spurious microwave modes and improve the readbacks. But the short plate almost cannot separate the frequencies of every mode. 


\section{References}

1. Y. Kang, G. Decker and J. Song, "Damping Spurious Harmonic Resonances in the APS Storage Ring Beam Chamber," Proceedings of the 1999 Particle Accelerator Conference, New York, 3092 (1999).

2. G. Decker, "Orbit Control at the Advanced Photon Source," Proceedings of the 5th European Workshop on Diagnostics and Beam Instrumentation, Grenoble, France, PM07 (2001).

3. MAFIA Version 4.0, Gesellschaft fur Computer-Simulationstechnik, Lauteschlagerstrate 38, D64289, Darmstadt, Germany. 